(2) Open Access Full Text Article

\title{
Pigment dispersion syndrome associated with intraocular lens implantation: a new surgical technique
}

This article was published in the following Dove Press journal:

Clinical Ophthalmology

10 November 2010

Number of times this article has been viewed

M Isabel Canut Jordana'

Daniel Pérez Formigó'

Rodrigo Abreu González ${ }^{2}$

Jeroni Nadal Reus'

'Barraquer Ophthalmology Centre, Barcelona, Spain; ${ }^{2}$ University Hospital of La Candelaria, Tenerife, Spain
Correspondence: MI Canut Jordana c/ Muntaner 314, 0802I, Barcelona, Spain $\mathrm{Tel}+34620212021$

Fax +34932002 469

Email mcanut@co-barraquer.es
Aims: We report the case of a myopic patient who, after intraocular lens transplant in the posterior chamber, suffered elevated intraocular pressure due to pigment dispersion, with recurrent episodes of blurred vision. The patient was treated with a new surgical technique that can avoid potential iridolenticular contact.

Methods: Complete ophthalmologic examination and optical coherence tomography (OCT) of the anterior segment were performed.

Results: Contact between the pigmentary epithelium and the iris with an intraocular lens was revealed by utrasound biomicroscopy and OCT. In this case, Nd:YAG laser iridotomy and laser iridoplasty were not effective for iridolenticular separation and control of the pigment dispersion. We propose a new technique: stitches on the surface of the iris to obtain good iridolenticular separation and good intraocular pressure control.

Conclusion: Stitches on the iris surface should be considered as optional therapy in pigmentary glaucoma secondary to intraocular lens implantation. This surgical technique can avoid potential iridolenticular contacts more definitively.

Keywords: pigmentary glaucoma, intraocular lens, optical coherence tomography, laser

\section{Introduction}

Pigmentary dispersion syndrome secondary to intraocular lens (IOL) implantation in the sulcus may be a potential problem with poor response to medical treatment. ${ }^{1-4}$ Good results have been obtained with Nd:Yag laser peripheral iridotomy and with argon laser iridoplasty. ${ }^{5,6}$

We report a case with poor response to conventional treatment, in which we developed a new surgical procedure by suturing the iris surface with prolene stitches in the iridolenticular contact zone.

\section{Case report}

A 61-years-old woman, surgically treated for right eye cataract 30 months before, attended the emergency department for blurred vision after trauma.

Biomicroscopic examination of the anterior segment revealed pseudophakia with small slight displacement of the IOL towards the nasal quadrant and marked iridopseudophakodonesis, tyndal positive, flare +3 , and retrolental pigment without evidence of vitreous in the anterior chamber. Gonioscopy showed an open angle with pigment deposits from 5 to 7 hours. Right eye intraocular pressure (IOP) was $26 \mathrm{mmHg}$. The posterior segment showed myopic fundus and uncorrected visual acuity was 0.65. Left eye biomicroscopic examination showed a posterior chamber IOL, no pigment 
dispersion, and a open angle without evident trabecular pigmentation.

We observed a good response with timolol $0.5 \%$ (Timoftol ${ }^{\circledR}$; MSD Laboratories, Whitehouse Station, NJ) and topical prednisolone acetate (Pred-Forte ${ }^{\circledR}$; Allergan Laboratories, Irvine, CA) administered twice daily for two weeks. One month later, tyndall was negative and IOP was $12 \mathrm{mmHg}$.

Two months later the patient attended our emergency department again. We observed a luxated IOL in the vitreous cavity. We therefore decided to perform a vitrectomy, relocation of the IOL to the anterior chamber, and extraction since this was an IOL with three points of support (Ioltech Stabibag hydrophilic intraocular lens; Bausch and Lomb, Rochester, NY), and scleral-sutured posterior chamber intraocular lens implantation (+4.00 D MA60MA Acrysoft ${ }^{\circledR}$ IOL; Alcon Laboratories, Fort Worth, TX).

Immediately after intervention we observed satisfactory evolution with the IOL in position and IOP of $18 \mathrm{mmHg}$.

At one and three months after IOL replacement, the patient suffered two episodes of intraocular hypertension. Both biomicroscopic examinations showed a wide chamber with pigment dispersion in the anterior chamber and a cornea with some old endothelial pigment. Intraocular pressures of, 30 and $50 \mathrm{mmHg}$ respectively were satisfactorily treated with a fixed combination of dorzolamide and timoftol (Cosopt ${ }^{\circledR}$; MSD Laboratories) and topical prednisolone acetate (Pred-Forte ${ }^{\circledR}$; Allergan Laboratories) administered twice daily.

At six months after IOL replacement, the patient again attended our emergency department, this time complaining of blurred vision. Examination revealed abundant pigment dispersion throughout the anterior chamber, marked iris concavity, and untreated IOP of $14 \mathrm{mmHg}$ (Figure 1). We performed a macular ophthalmoscopy and optical coherence tomography to (OCT) (Visante ${ }^{\circledR}$; Carl Zeiss Meditec, Inc., Jena, Germany) to look for a cystoid macular edema but no macular disorder was found. At this point we considered a possible diagnosis of pigment dispersion due to iridolenticular contact. OCT of the anterior segment showed iris concavity produced by contact between the posterior face of the iris and the anterior face of the crystalline lens (Figure 2). This finding led to the performance of $\mathrm{Nd}$ :YAG laser iridotomy which rectified the iris concavity.

At successive check-ups we observed good iridolenticular separation in the right eye, permeable iridotomies, anterior chamber without celularity, and IOP of $10 \mathrm{mmHg}$.

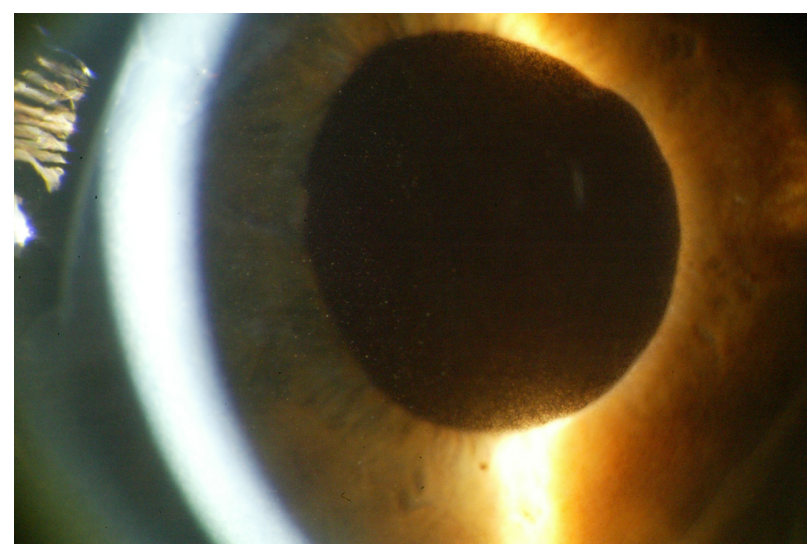

Figure I Intense pigment dispersion in the anterior chamber and large chamber amplitude after intraocular lens replacement.

Two months after Nd:YAG laser iridectomy, the patient reported a new episode of blurred vision. Examination showed extensive pigment dispersion in the anterior chamber, with right eye IOP of $12 \mathrm{mmHg}$. After two months of medical treatment (topical prednisolone acetate and tapered oral prednisone) without clinical improvement, we performed $360^{\circ}$ iridoplasty of the peripheral iris, which achieved good anatomic resolution but required maintenance therapy with antiglaucoma medication and topical nonsteroidal antiinflamatory drugs to conserve good visual acuity. Pilocarpine eye drops were used previously to check the contractility of the iris, finding a poor response.

Twelve months after the iridoplasty, the patient had new episodes of blurred vision caused by dispersion of pigment in the anterior chamber, which was resolved with nonsteroidal anti-inflammatory drugs and topical beta blockers (Figure 3). A repeat OCT of the anterior segment showed iridolenticular contact.

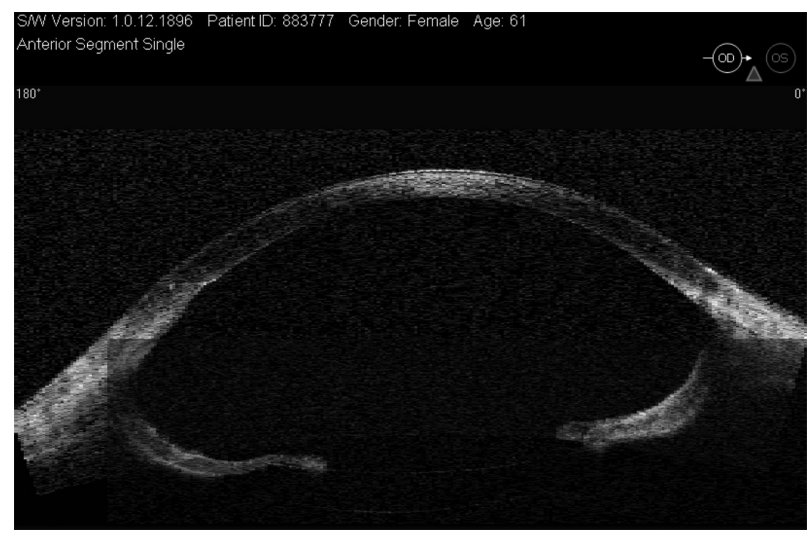

Figure 2 Photocomposition of optical coherence tomography images of the anterior segment. Note the pronounced iris concavity, the reverse pupillary block, and the iridolenticular contact that produced pigment dispersion. 


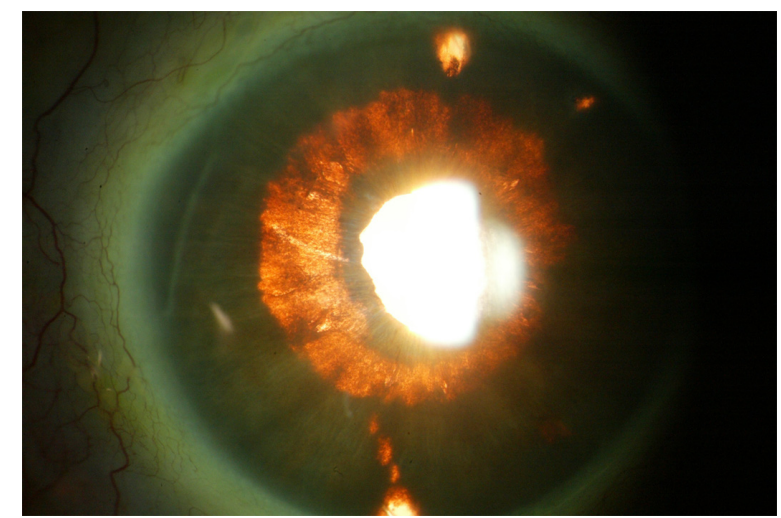

Figure 3 Iris transillumination in slit lamp examination, clearly showing pigmentary defect in the areas of chronic rubbing due to iridolenticular and intraocular lens haptic contact with the posterior face of the iris.

Given the chronic nature of the case and the refusal of the patient to undergo IOL removal or repositioning of the IOL in the anterior chamber despite good endothelial cell count, we decided to perform a more conservative surgery consisting of placing four prolene 10/0 stitches (Ethicon Inc, Somerville, NJ) on the iris surface to permanently remove the iridolenticular contact (Figure 4). The technique consists of performing three paracentesis, two of them in each of the margins of the area affected by the pigment dispersion, and a third at the midpoint. In this way we could access the area to be treated by adjusting the different stitches and were thus able to lift the flaccid iris, and eliminate the iridolenticular contacts.

Six months after placement of the prolene stitches in the iris, we observed good tolerance (Figure 5), an absence

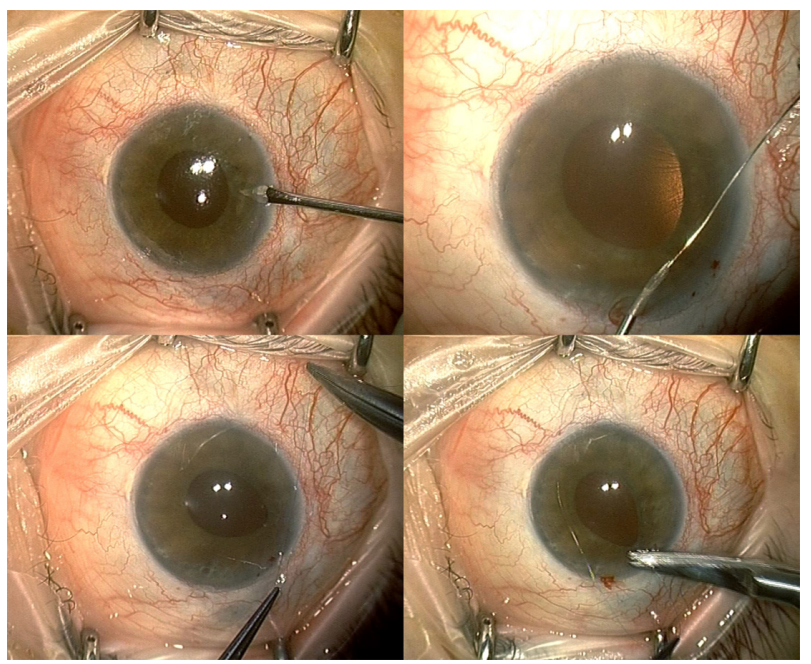

Figure 4 Details of the placement of prolene stitches in the area of the iris that we raised to avoid iridolenticular contact.

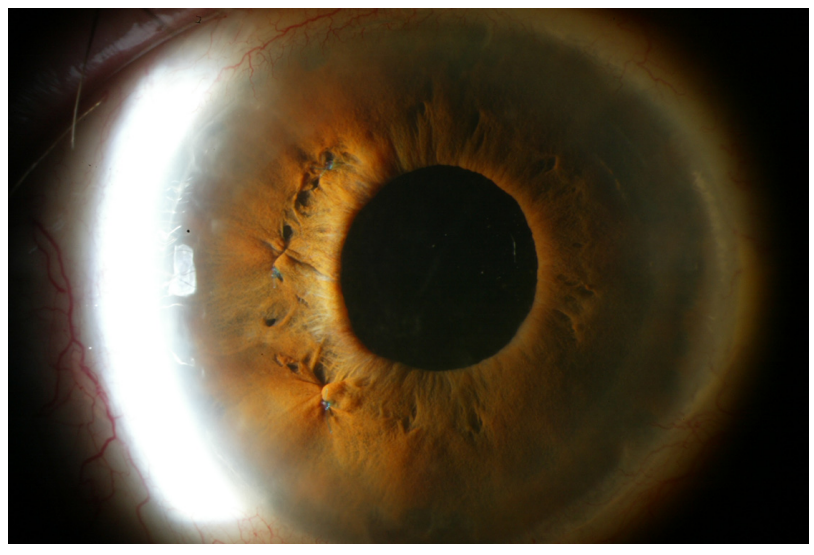

Figure 5 Six months later. Anterior chamber without pigment dispersion and iris prolene stitches well tolerated at 7, 9, and II hours.

of pigment dispersion in anterior chamber, and a good iridolenticular separation in the OCT (Figure 6). Without antiglaucoma medication, uncorrected visual acuity was 0.65 , and an IOP of $17 \mathrm{mmHg}$.

\section{Discussion}

Pigment dispersion syndrome (PDS) is produced when iris pigmentary epithelium pigment deposits pass through the aqueous humor and are dispersed throughout the anterior segment. When this dispersion is associated with increased IOP, it is called pigmentary glaucoma (PG), which must be taken into account on evaluating primary open-angle glaucoma. ${ }^{1}$

The literature contains cases of PG secondary to IOL implantation in the posterior chamber. Among the different theories attempting to explain this increase of IOP, the most widely accepted proposes that chronic contact between the haptics and the posterior face of the iris triggers pigment release. This, together with the localization of iris transillumination defects and increased IOP months after intervention,

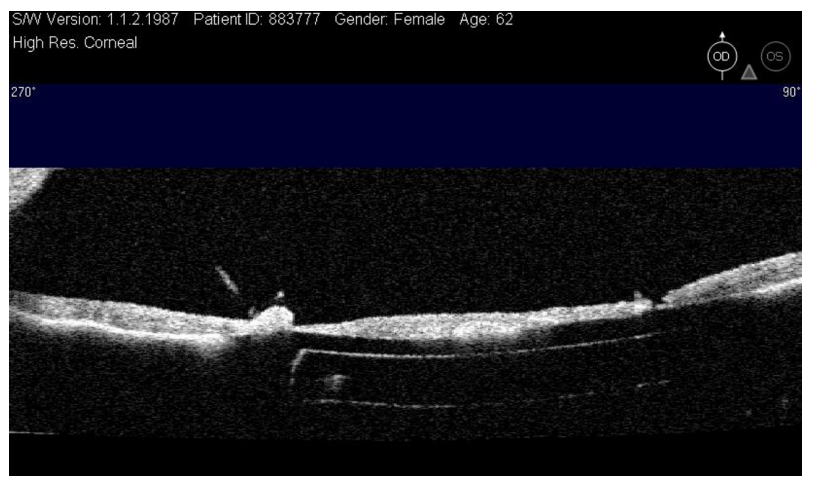

Figure 6 Detail showing iridolenticular separation after prolene 10/0 stitches optical coherence tomography. 
suggests that the IOL is the most probable cause. ${ }^{2}$ The thickness, size, material, implantation technique, and the degree of inclination of the haptics are factors that influence changes in the iris. ${ }^{3}$

Anterior segment optical coherence tomography (AS-OCT) is a high resolution noninvasive technique allowing rapid in vivo evaluation of possible iridolenticular contact, as well as visualization of anatomic details such as iris concavity, amplitude, and angle of the anterior chamber., ${ }^{4,5}$

In order to equalize anterior and posterior chamber pressure, many authors propose the use of $\mathrm{Nd}$ :YAG laser iridotomy, with confirmation of iris flattening by ultrasound biomicroscopy. Although most cases prove anatomically successful (with restitution of the iris in its anatomic position), pressure control is often not achieved. This explains why the efficacy of YAG laser iridotomy in pigmentary glaucoma is not generally established. ${ }^{6}$

Considering the physiopathologic mechanisms of pigmentary glaucoma and the mechanism of action of argon laser iridoplasty (which aims to provoke contraction of the peripheral iris and flattening of the peripheral curvature using the thermal effect of the laser), we believe that this method could be useful for this type of pathology, reducing iris concavity and avoiding "reverse pupillary block" and the consequent increase of intraocular pressure. However, this hypothesis requires prolonged studies with greater numbers of patients to determine its possible indication and long-term benefits.

Pigment dispersion syndrome secondary to IOL implantation in the sulcus and mainly if haptic-optic angulation is present as in the case described (MA60MA Acrysoft $^{\circledR}$ IOL, Alcon Labs) may prove refractory to medical treatment and require coadjuvant laser treatment (such as iridotomy or iridoplasty), to correct episodes of pigment dispersion by minimizing iris-optic and iris-haptic contact.

When the laser treatment is not sufficient to reverse this process, different authors propose explants or IOL exchange to solve the pigment dispersion..$^{7-10}$ In our case, the refusal of the patient to agree to IOL removal and due to the clearly identified iridolenticular contact, we decided to perform surgery that involved stitches to the surface of the iris in order to lift the iris and separate it from the IOL. As this is a new technique, we need more follow-up time and a larger series of patients, to confirm this method as an alternative surgical treatment when conventional laser (iridotomy and iridoplasty) does not resolve the iridolenticular contact.

If the stitches do not suceed, we propose removal of the IOL to prevent chronic evolution of pigment loss.

\section{Disclosure}

No conflicts of interest were declared in relation to this paper.

\section{References}

1. Detry-Morel ML, van Acker E, Pourjavan S, Levi N, de Potter P. Anterior segment imaging using optical coherence tomography and ultrasound biomicroscopy in secondary pigmentary glaucoma associated with in-the-bag intraocular lens. J Cataract Refract Surg. 2006; 32(11): 1866-1869.

2. Brandt JD, Mockovak ME, Chayet A. Pigment dispersion syndrome induced by a posterior chamber phakic refractive lens. Am J Ophthalmol. 2001;131(2):260-263.

3. Ballin N, Weiss DM. Pigment dispersion and intraocular pressure elevation in pseudophakia. Ann Ophthalmol. 1982;14:627-630.

4. Puliafito CA, Hee MR, Schuman JS, Fujimoto JG. Optical Coherence Tomogaphy of Ocular Diseases. Thorofare, NJ: Slack;1996.

5. Méndez-Hernandez C, García-Feijoó J, Cuiña-Sardiña R, GarcíaSánchez J. Estudio de glaucoma pigmentario mediante biomicroscopia ultrasónica. Arch Soc Esp Oftalmol. 2003;78:137-142.

6. Potash SD, Tello C, Liebmann J, Richt R. Ultrasound biomicroscopy in pigment dispersion syndrome. Ophthalmology. 1994;101:332-339.

7. Chang WH, Werner L, Fry LL, Johnson JT, Kamae K, Mamalis N. Pigmentary dispersion syndrome with a secondary piggyback 3-piece hydrophobic acrylic lens. Case report with clinicopathological correlation. J Cataract Refract Surg. 2007;33(6):1106-1109.

8. ASCRS Cataract Clinical Committee. Complications of sulcus placement of single-piece acrylic intraocular lenses: recommendations for backup IOL implantation following posterior capsule rupture. J Cataract Refract Surg. 2009;35(8):1445-1458.

9. Chang SHL, Lim G. Secondary pigmentary glaucoma associated with piggyback intraocular lens implantation. J Cataract Refract Surg. 2004; 30:2219-2222.

10. Kohnen T, Kook D. Solving intraocular lens-related pigment dispersion syndrome with repositioning of primary sulcus implanted singlepiece IOL in the capsular bag. J Cataract Refract Surg. 2009;35(8): 1459-1463.

Clinical Ophthalmology

\section{Publish your work in this journal}

Clinical Ophthalmology is an international, peer-reviewed journal covering all subspecialties within ophthalmology. Key topics include: Optometry; Visual science; Pharmacology and drug therapy in eye diseases; Basic Sciences; Primary and Secondary eye care; Patient Safety and Quality of Care Improvements. This journal is indexed on Submit your manuscript here: http://www.dovepress.com/clinical-ophthalmology-journal

\section{Dovepress}

PubMed Central and CAS, and is the official journal of The Society of Clinical Ophthalmology (SCO). The manuscript management system is completely online and includes a very quick and fair peer-review system, which is all easy to use. Visit http://www.dovepress.com/ testimonials.php to read real quotes from published authors. 